\title{
David Oliver: Fear in medical practice
}

\author{
David Oliver consultant in geriatrics and acute general medicine
}

Berkshire

Last week Helen Salisbury wrote in her BMJ column about the fear of getting things wrong as a GP. ${ }^{1}$ Medical practice, by its nature and the disposition of many doctors, has always entailed worry, however well trained or confident we are. But, if worry becomes more generalised anxiety or escalates to fear, the threat to our mental health or ability to function in demanding jobs seems stark.

The BMA recently published a report on what needs to change to improve NHS doctors' working lives. ${ }^{2}$ Before reading it I'd become conscious of growing fear and anxiety, in myself and in colleagues. If I was running scared-a long serving doctor, secure in my job, with a series of national leadership roles behind me-then wasn't this a wider problem?

There are some clear pressure points. These were elegantly categorised in a recent article in the BMA's The Doctor as "systemic, endemic, interpersonal, environmental, and sociocultural."” A continually under-resourced, short staffed system, increasingly unable to meet rising demand, begins to feel unsafe. Care can be rushed or missed. There's relentless pressure to discharge people or prevent them being admitted. The sheer number of patients and families we support each day, and the imperative to work at speed and minimise delays, means corner cutting and workarounds.

We have to accept, balance, and mitigate risk to patients, even as systems outside hospital are under even more strain. We work on wards facing epic nursing shortfalls, often with inadequate IT or logistics. Even if our own decisions and communication are sound, there's much else we can't control.

Add to this the growing complexity of patients on our caseload, relentless political and media scrutiny of the NHS, and growing public expectation and dissatisfaction (often with aspects of care we have no power over), and anxiety seems inevitable.

As the GP Jonathon Tomlinson argued in a 2016 lecture, ${ }^{4}$ uncertainty is possibly the largest factor behind doctors' anxiety. And, despite the rise in evidence based medicine, protocols, and decision tools, the causes of uncertainty go well beyond individual clinical decisions.

NHS doctors increasingly fear blame or formal complaints (whether or not they're personally at fault), regulatory action, or loss of livelihood or reputation. We may fear for our sleep, mental or physical health, or ability to keep on going in our career. We may worry about the job's impact on our family. Fear of inability to sustain our career into our 60 s is common. We may also fear losing our hard won skills, not having the time to keep them up to date, and no longer being safe or competent in our practice.

Maybe we also fear that, if we do have health problems or perhaps resort to addictive behaviours to cope with them, this will come to light and damage us further. Endemic staffing gaps and our loyalty to patients and colleagues are strong imperatives to keep going when perhaps we should not. When generalised chronic anxiety takes hold, some worries can be blown out of proportion so that we lose our peace of mind-not from what has happened but from what we imagine might happen.

The BMA's Chaand Nagpaul said at the report's launch that the NHS now had a culture "where blame stifles learning, contributing to the vicious cycle of low morale so staff leave. This unsafe, underfunded environment is as damaging for patients as it is for doctors." 5

The evidence set out in the BMA report supports that view. I wonder how many readers feel as scared as I often do these days, and how we doctors might help solve the problem of fear.

Competing interests: See https://www.bmj.com/about-bmj/freelance-contributors. Provenance and peer review: Commissioned; not externally peer reviewed.

1 Salisbury H. Helen Salisbury: Reasons to be fearful. BMJ 2019;367:I578610.1136/bmj.15786.

2 BMA. Caring supportive collaborative: a manifesto for change. 9 Sep 2019. https://www. bma.org.uk/collective-voice/policy-and-research/nhs-structure-and-delivery/future-visionfor-the-nhs/caring-supportive-collaborative-manifesto.

3 Cooper K. Pressure points. Doctor 2019 Oct 10. https://www.bma.org.uk/news/2019/ october/pressure-points.

4 Tomlinson J. Anxiety and the medical profession. A Better NHS 2016 May 10. https:// abetternhs.net/2016/05/10/anxiety-and-the-medical-profession/.

5 Mahase E. BMA calls for legislation to stop doctors being blamed when under "unmanageable pressure". BMJ 2019;366:|5557. 10.1136/bmj.|l5557 31519729

Published by the BMJ Publishing Group Limited. For permission to use (where not already granted under a licence) please go to http://group.bmj.com/group/rights-licensing/ permissions 
